\title{
ACESSIBILIDADE E SEGURANÇA NA EVACUAÇÃO EM CASO DE INCÊNDIO ENVOLVENDO PESSOAS COM DEFICIÊNCIA
}

\author{
Kissia Stein do Nascimento ${ }^{1}$ \\ João Carlos Souza ${ }^{2}$
}

\section{RESUMO}

Este artigo investiga a relação entre normativas de acessibilidade e normativas de segurança em caso de incêndio envolvendo pessoas com deficiência. Tem como objeto de estudo as propostas de texto para revisão de duas Instruções Normativas do Corpo de Bombeiros Militar de Santa Catarina: a IN 009/DAT/CBMSC - Sistema de Saídas de Emergência e a IN 027/DAT/CBMSC - Brigada de Incêndio. Por meio de uma revisão bibliográfica e associando normativas federais e estaduais sobre a mesma temática, avalia as atualizações referentes à acessibilidade propostas nos textos que estiveram disponíveis para consulta pública pela Diretoria de Atividades Técnicas do Corpo de Bombeiros Militar de Santa Catarina. Considera a importância da identificação de aspectos de acessibilidade relacionados à segurança em uma evacuação emergencial como forma de conferir melhores condições de movimentação das pessoas, minimizando riscos e consequências de acidentes. Pretende contribuir para ampliar o debate relativo à acessibilidade e à segurança na evacuação em caso de incêndios.

Palavras-chave: Acessibilidade; Pessoas com Deficiência; Segurança; Incêndio; Evacuação.

\footnotetext{
${ }^{1}$ Arquiteta e urbanista. Especialista em Direito à Cidade e Gestão Urbana, e-mail: kissiastein@yahoo.com.br

2 Doutor, Professor e Orientador no Programa de Pós-Graduação em Arquitetura e Urbanismo da Universidade Federal de Santa Catarina, e-mail: joao.carlos@ufsc.br
} 


\title{
ACCESSIBILITY AND SAFETY IN FIRE EVACUATION FOR PEOPLE WITH DISABILITIES
}

\begin{abstract}
This article investigates the relationship between accessibility regulations and safety regulations in case of fire with people with disabilities. The object of study is the text proposals for revision of two Normative Instructions of the Fire Brigade of Santa Catarina: the IN 009/DAT/CBMSC - Emergency Exit System and the IN027/DAT/CBMSC - Fire Brigade. Based on a bibliographical review and involving federal and state regulations on the same theme, it evaluates the accessibility updates proposed in the texts that were available for public consultation by the Technical Activities Directorate of the Santa Catarina Military Fire Brigade. It considers the importance of identifying aspects of accessibility related to safety in an emergency evacuation as a way to give better conditions of movement of people, minimizing risks and consequences of accidents. It intends to contribute to broadening the debate on accessibility and safety in fire evacuation
\end{abstract}

Keywords: Accessibility; People with disabilities; Safety; Fire; Evacuation.

Artigo Recebido em 14/01/2019 - Aceito em 22/03/2019 - Publicado em 31/03/2019 


\section{INTRODUÇÃO}

A necessidade de atualização de prescrições normativas, em face das evoluções tecnológicas e científicas, novos conceitos e legislação (Lei $n^{\circ}$ 13.146/2015 e Lei 13.425/2017), oportunizou o interesse por esta pesquisa. A partir da observação do processo de revisão de normativas do Corpo de Bombeiros Militar de Santa Catarina (CBMSC), em específico as normativas referentes a Saídas de Emergência e a Brigadas de Incêndio, foi avaliada a incorporação de questões de acessibilidade referentes à evacuação de pessoas com deficiência em caso de incêndio através de um sistema passivo de proteção a incêndio (saídas de emergência) e de um sistema ativo (brigadas). Além da revisão das normativas na esfera do estado de Santa Catarina (SC), verificou-se que as normativas semelhantes na esfera federal (NBR 9077 Saídas de emergência em edifícios e NBR 14276 Brigada de incêndio - Requisitos) também estão em processo de revisão.

Para este estudo, considerou-se a importância do esvaziamento rápido e seguro dos locais, a fim de proteger vidas. A acessibilidade foi considerada como um fator capaz de oferecer igualdade de oportunidade para transitar por espaços públicos ou privados, com conforto, segurança e autonomia, reduzindo ao máximo as barreiras. Em todos os tipos de edificações de uso coletivo é obrigatório $\mathrm{o}$ atendimento às normas de acessibilidade e às normas de proteção e combate a incêndio. Elas são fundamentais para a preservação da integridade física e da vida das pessoas com alguma deficiência ou mobilidade reduzida. Também é necessário que estes locais apresentem dispositivos e estratégias que direcionem essas pessoas para locais seguros durante uma situação de emergência. Vale ressaltar que uma pessoa com deficiência auditiva não consegue ouvir um alarme de incêndio, assim como uma pessoa com deficiência visual não consegue ver a sinalização de evacuação, e uma pessoa que utiliza cadeira de rodas não pode fugir pela escada. Desta forma, mesmo a acessibilidade sendo um tema transversal a ser aplicado nos projetos 
para edificações, no caso das instalações de combate a incêndio é importante que o tema seja contemplado nos códigos e normas que regem este tipo de instalação, evitando conflitos nas indicações de parâmetros projetuais e procedimentos.

A contextualização do problema foi realizada a partir de uma revisão teórica que busca entender as principais dificuldades para a evacuação emergencial de edificações envolvendo pessoas com deficiências motoras, visuais e auditivas e através da análise das normas de segurança existentes mais relevantes sobre o encaminhamento e a evacuação de pessoas com deficiências em situações de emergência. $\mathrm{Na}$ análise das saídas de emergência, considerou-se o deslocamento e a orientação espacial. Já na análise referente à Brigada de Incêndio, considerou-se o comportamento humano em situação de risco e as políticas de segurança (capacitações, treinamentos, práticas e simulações de abandono para retirada de pessoas com deficiência em caso de sinistro).

\section{ACESSIBILIDADE NA REVISÃO DA IN 009/DAT/CBMSC E DA IN 028/DAT/CBMSC}

\section{REFERENCIAL TEÓRICO}

\section{Acessibilidade}

A Lei Brasileira de Inclusão da Pessoa com Deficiência (Lei 13.146/2015) define acessibilidade como:

Possibilidade e condição de alcance para utilização, com segurança e autonomia, de espaços, mobiliários, equipamentos urbanos, edificações, transportes, informação e comunicação, inclusive seus sistemas e tecnologias, bem como de outros serviços e instalações abertos ao público, de uso público ou privados de uso coletivo, tanto na zona urbana como na rural, por pessoa com deficiência ou com mobilidade reduzida (BRASIL, 2015). 
Dischinger et al. (2012: 16-17) diferenciam os termos deficiência, incapacidade e restrição, defendendo que em um ambiente acessível não existe incapacidade para qualquer tarefa e o indivíduo não sofre restrição. As autoras conceituam a deficiência como uma disfunção no nível fisiológico do indivíduo, que resulta em perda ou redução das suas habilidades. Já a restrição é conceituada como dificuldade na realização de atividades devido a relação entre as condições do indivíduo e as características do ambiente no qual está inserido (as habilidades não são suficientes para transpor as barreiras do espaço).

As pesquisadoras classificam as deficiências em quatro grupos distintos, a partir das características perdidas pela deficiência: físico-motora, sensorial, cognitiva e múltipla. Entre as pessoas com deficiência físico-motoras estão usuários de cadeiras de rodas, muletas ou bengalas, assim como aqueles cuja alteração da capacidade de motricidade afeta a realização de atividades que demandam força física e/ou coordenação motora. No grupo de pessoas com deficiência sensorial estão as com deficiências visual, auditiva, háptica (relativo à sensibilidade ao toque), paladar-olfativa e no sistema de orientação/equilíbrio. As pessoas com deficiência cognitiva incluem as que apresentam dificuldades para a compreensão e tratamento das informações recebidas, podendo afetar processos de aprendizado, comunicação e tomada de decisão. A deficiência múltipla corresponde às pessoas com duas ou mais deficiências associadas.

Além de pessoas com alguma deficiência, também há pessoas que se encontram com a mobilidade reduzida. Conforme define a Lei 13.146/2015, são aquelas que, por qualquer motivo, apresentam dificuldade de movimentação, permanente ou temporária, gerando redução efetiva da mobilidade, flexibilidade, coordenação motora ou percepção, incluindo idoso, gestante, lactante, pessoa com criança de colo e obeso. Estas pessoas também podem demandar alterações no espaço para que possam utilizá-lo.

Ampliando o conceito de acessibilidade em direção ao Desenho Universal, Duarte e Cohen (2006, p.3) afirmam que 
... a acessibilidade ao espaço construído não deve ser compreendida como um conjunto de medidas que favoreceriam apenas às pessoas com deficiência - o que poderia até aumentar a exclusão espacial e a segregação destes grupos, mas sim medidas técnico-sociais destinadas a acolher todos os usuários em potencial.

Dischinger et al. (2012, p.18) complementam, definindo que

Acessibilidade espacial significa bem mais do que poder atingir um lugar desejado. É também necessário que o local permita ao usuário compreender sua função, sua organização e relações espaciais, assim como participar das atividades que ali ocorrem.

Para melhor compreender a acessibilidade espacial e orientar as ações de avaliação e fiscalização do ambiente, Dischinger et al. (2012: 28) dividem este conceito em quatro componentes com diretrizes e características espaciais, sendo eles: orientação espacial, comunicação, deslocamento e uso. Para garantir que todas as pessoas possam utilizar determinado espaço ou percurso, as autoras afirmam que é necessário que os componentes sejam atendidos em sua totalidade, pois a ausência de um desses componentes compromete os demais.

Desta forma, os profissionais responsáveis pela elaboração de projeto devem considerar, desde a fase inicial do trabalho, as questões relacionadas à acessibilidade, pois pequenos erros podem dificultar e impossibilitar o uso de determinado espaço por alguns usuários, resultando em espaços deficientes.

Visando que todos os indivíduos possam usufruir dos mesmos direitos, o Decreto-Lei Federal 5.296/2004 estabeleceu a obrigatoriedade da consideração dos parâmetros apresentados pela NBR 9050 - Norma Brasileira de Acessibilidade a edificações, mobiliário, espaços e equipamentos públicos.

É necessário eliminar barreiras que comprometam a participação dos indivíduos nos ambientes. Para Dischinger et al. (2012: 14), estas barreiras podem ser classificadas de duas formas: barreiras físico-espaciais (permanentes ou dinâmicas) e barreiras atitudinais (relações interpessoais). 
Vale lembrar que estas considerações se aplicam ao acesso e a evacuação de ambientes, pois situações de risco geram pânico e potencializam as dificuldades de deslocamento de pessoas com ou sem deficiência. Desta forma, ambientes acessíveis conferem melhores condições de movimentação em situações emergenciais para todas as pessoas, sejam elas com ou sem deficiência, visto que a mobilidade poderá estar reduzida temporariamente em função da luminosidade e do comportamento em pânico.

\section{Segurança}

Segundo Cardella (2012 apud BOMBRILLA, 2014, p.34), a palavra segurança significa a variável inversa do risco. Logo, quanto maior a segurança, menor é o risco e vice-versa. Para mitigar o perigo de sinistros ou desastres, sejam eles por causas naturais ou tecnológicas, a adoção de medidas de segurança é fundamental.

Entre os desastres tecnológicos, os incêndios urbanos se destacam pela frequência de ocorrência, dificuldade de previsão e pelas consequências trágicas de sua rápida propagação. Além disso, se originam de ações, negligências ou omissões humanas (projetistas, executores, fiscais, usuários), apresentando, portanto, maiores possibilidades de prevenção. Entre as medidas preventivas, volta-se a atenção para as normas de segurança, uma vez que a partir delas podem ser evitadas ocorrências ou mitigadas consequências através da adoção de medidas de segurança e treinamento de ocupantes.

Conforme Drury e Cocking (2007), a precisão da percepção do risco em relação às fontes de ameaça e seu grau de importância são determinantes para a sobrevivência ou não de um ocupante em um desastre. Após o alerta de emergência, a capacidade cognitiva depende de um processo psicológico, de aspectos subjetivos de avaliação da probabilidade de ser afetado ou não por um evento indesejado, em uma situação específica e uma percepção da própria segurança e dos recursos de enfrentamento disponíveis (LIMA, 2017). 
Esta percepção individual de riscos é variável e interfere diretamente na tomada de decisão, pois pessoas reagem de formas diversas aos sinais de perigo e possuem condições de ação individualizadas. É possível que determinados ocupantes entrem em estado de pânico e não consigam reagir prontamente, percam parcial ou totalmente sua capacidade de raciocínio lógico, fiquem paralisados e/ou estejam mais propensos a repetir ações de outras pessoas de forma desatenta. É importante considerar as características dos ocupantes da edificação, incluindo a possibilidade da presença de pessoas com deficiência e/ou com dificuldade de mobilidade, que podem necessitar de auxílio de terceiros nos casos de evacuação. Em situações de risco iminente é fundamental que existam pessoas bem instruídas, treinadas e preparadas, que compreendam os sinais de alerta, assumam uma posição de liderança e sirvam de guia para os demais, sinalizando os melhores caminhos, as possibilidades de proteção existentes e as ações mais eficazes a serem tomadas.

\section{Dificuldades de Evacuação}

Kinateder et al. (2015) dividem o processo de evacuação em três momentos significativos: o pré-alarme (ativação automática do alarme ou provocada por algum usuário), a pré-evacuação (efetivo funcionamento do alarme,seguido do momento da tomada de decisão de abandonar ou não o local, podendo ser mais longo que o período da própria evacuação) e a evacuação propriamente dita.

Além da forma com que os ocupantes percebem e reagem a situações de risco e do tempo disponível para o esvaziamento, outros fatores dificultam o abandono dos locais, tais como as características espaciais do local e sua utilização, o elevado número de ocupantes, a dependência física e psíquica dos usuários, a complexidade de gerenciar multidões e o próprio pânico. É necessário considerar dificuldades cognitivas e dificuldades espaciais para a organização de rotas que permitam o fluxo adequado, para que 0 
deslocamento ocorra dentro de um espaço de tempo seguro e de forma ordenada (LIMA, 2017).

Gouveia e Etrusco (2002, p.258) associam a familiaridade do usuário com o espaço e a eficiência da sinalização de emergência no contexto do uso da edificação aos parâmetros que podem influir na severidade de um incêndio. Desta forma, é essencial que além de pessoas instruídas para orientar a evacuação, existam rotas bem planejadas, adequadamente dimensionadas e livres de obstáculos para possibilitar o esvaziamento rápido e seguro, impedindo ou mitigando os impactos negativos do sinistro.

Pessoas com deficiência em situações de incêndio

Em situações de incêndios, as pessoas com deficiência e/ou mobilidade reduzida deverão ter as mesmas oportunidades que as demais. Para tal, são necessárias algumas estratégias alternativas de evacuação com, no mínimo, o mesmo nível de segurança, para que todos os ocupantes atinjam um ponto seguro no edifício durante a evacuação. Reis (2014, p.20) salienta que isto não implica que a forma de evacuação seja igual ou pelo mesmo percurso.

Reis (2014) apresenta estudos realizados por Juillet (1993) a respeito do tempo médio e os meios de evacuação em incêndio ocorrido em edificação com pessoas com deficiência, indicando caso de utilização de escadas com o auxílio de outros ocupantes (na ausência de entidades competentes de evacuação, as pessoas com deficiência aceitam ser auxiliadas por colegas e/ou ocupantes do edifício) ou da equipe de emergência.

Estudos de Boyce et al. (1999), apresentado por Reis (2014), abordam a previsão do número e das características das pessoas com deficiência passíveis de frequentar edifícios que recebem público, com e/ou sem assistência. Os mesmos autores estudam as principais dificuldades dos ocupantes durante a evacuação, indicando pequenos degraus e abertura de portas ao nível da subida e descida de escadas. Boyce et al. (1999) estudam a respeito de velocidades médias ascendentes e descendentes para 0 
deslocamento em vias horizontais, verticais e em rampas, de acordo com o nível de assistência dos ocupantes (Com dificuldade de deslocamento; Sem ajuda; De muletas; De bengala; De andarilho; Sem dificuldade de deslocamento; Em cadeira de rodas elétrica; Em cadeira de rodas manual; Em cadeira de rodas manual com assistência; Ambulante com assistência; Pessoas que podem andar, mas com dificuldade ou que têm uma deficiência que afeta a marcha ou que não têm pleno uso de pelo menos um braço ou mão ou que carecem de coordenação), constatando que em vias horizontais a movimentação com cadeira de rodas manual com assistência tem a maior velocidade de deslocamento, enquanto no movimento ascendente e descendente de vias verticais e de rampas de evacuação, a maior preocupação refere-se a pessoas com deficiências ao nível da visão e audição, sendo a velocidade de deslocamento ligeiramente superior no movimento decrescente em rampas e na subida a via da escadas é mais rápida. Os autores destacaram ainda a importância da inclusão dos tempos de repouso e de mudança de direção no cálculo do tempo de evacuação de pessoas com dificuldades de deslocamento, assim como a importância dos acessórios de apoio ao deslocamento, como corrimãos e a posição das portas na direção do percurso de evacuação, e a influência das dificuldades visuais na evacuação (sinais LED são indicados, pois são os mais visíveis e legíveis).

Nas publicações da International Association for Fire Safety Science (IAFSS), pesquisas de Samoshin e Istratov (2014) abordam a segurança de pessoas com deficiência visual em caso de incêndio, pesquisas de Tsuchiya et al. (2007) simulam a evacuação de pessoas em cadeira de rodas (largura das passagens, fluxo e velocidade de deslocamento), e pesquisas de Furukawa et al. (2007) tratam da influência da presença de idosos em situação de incêndio (Diminuição da sensibilidade e do movimento e consequente diminuição da velocidade média de deslocamento, sendo necessário analisar o impacto da fadiga no processo de evacuação). 
Em seu "Emergency evacuation planning guide for people with disabilities", a National Fire Protection Association" (NFPA) considera para evacuação de pessoas com deficiência aquelas com dificuldades de deslocamento, deficiências de visão, audição e dificuldades cognitivas, problemas cardíacos ou respiratórios permanentes ou temporários, assim como grávidas e crianças. A NFPA considera que o mínimo para o planejamento da evacuação para pessoas com deficiência em situação de emergência envolve a forma de notificação da emergência, a definição do caminho/rota de evacuação (e respectivas indicações), o meio de circulação (o próprio, auxiliado por outro ou por dispositivos mecânicos) e as respostas às perguntas quem? como/por que meio? onde/por onde? quando? A NFPA contempla a utilização de animais como meio de transmissão e condução de pessoas com deficiência, os planos de evacuação de edifícios contemplando a atuação em caso de evacuação de pessoas com diferentes tipos de deficiência e, desde 1991, introduziu o uso de elevadores de emergência em áreas de refúgio, com especificações técnicas rigorosas (quanto à carga e capacidade, sistema de detecção, de alarme, alerta e proteção de incêndio e saídas de emergência) que poderão ser utilizados com meio alternativo de saída de emergência.

Reis (2014, p.20) indica que

Algumas estratégias facilitadoras da evacuação de pessoas com necessidades especiais em situação de emergência têm sido desenvolvidas e amplamente aplicadas em edifícios que recebem público. Como criação de zonas de refúgio complementadas de compartimentação resistente ao fogo adequada, disponibilização de elevadores de evacuação e estratégia buddy system que define uma ou mais pessoas a quem é atribuída a responsabilidade de evacuar a pessoa com necessidade (utilizado com maior frequência em ambientes de trabalho do que em espaços que recebem público).

Complementando estas estratégias, Hamilton (2009) recomenda que o número de pessoas com necessidades especiais seja conhecido, bem como o tipo da necessidade, o que tornaria possível criar um registro que identifique o risco setorialmente e indique as melhores alternativas de evacuação para cada 
caso. Somando a isso, Proulx (2002) indica que estratégias diversas devem ser escolhidas para a evacuação de edificações, de acordo com o tipo de incêndio e a configuração da edificação. Ressalta-se que no caso das estratégias para proteção in loco é necessária a permanência de alguns ou de todos os ocupantes no prédio durante um incêndio em áreas de refúgio ou resgate (compartimento de segurança resistente ao fogo e fumaça) até que os bombeiros controlem a situação ou o resgate. No caso das estratégias para evacuação da edificação com a retirada dos ocupantes, as pessoas com dificuldades de mobilidade podem evacuar usando elevadores seguros específicos, ou serem auxiliadas para descer as escadas ou rampas.

Observa-se, então, como colocado por Reis (2014, p.21), que para uma resposta eficaz de um edifício, as condições de resistência e reação ao fogo dos componentes do próprio edifício são conciliadas com a formação e 0 treinamento adequados de seus utilizadores, visto que a restrição ou a limitação na mobilidade pode demandar soluções mais elaboradas de logística humanitária, envolvendo maior número de pessoas.

Neves et al. (2008) pontuam algumas das especificidades relativas a pessoa com deficiência auditiva, pessoa com deficiência visual e pessoa com deficiência fisco-mota e/ou mobilidade reduzida, ressaltando que a familiaridade do indivíduo com o edifício refletirá na probabilidade de sobreviver a um incêndio. Uma pessoa com deficiência auditiva não consegue ouvir um alarme de incêndio, podendo ficar vulnerável, por conta de eventual atraso no conhecimento do alerta, comprometendo a sua segurança. Nestes casos é necessária uma detecção precoce e um alarme perceptível (visual, vibratório), visto que os alarmes de incêndio e evacuação são tipicamente baseados em som. A pessoa com deficiência visual não consegue identificar exatamente a origem do incêndio (mesmo de pequenas dimensões), tendo menor probabilidade de conseguir extingui-lo, podendo até mesmo se tornar uma ameaça. Por não conseguir ver a sinalização de evacuação, o primeiro sinal de um incêndio, em geral, será o cheiro e o calor provenientes do fogo. Logo, as 
referências deverão se basear em informações auditivas (alarme e instruções sonoras ou vocalizadas por pessoas treinadas) e marcas ou indicações táteis da localização de saídas de emergência. Já uma pessoa que utiliza cadeira de rodas não pode fugir pela escada. Conforme a adaptação e prática que tenha com a cadeira de rodas,ela pode se deslocar com agilidade em busca de uma saída via rampa, elevador de segurança ou se direcionando a uma área de resgate protegida.

\section{METODOLOGIA}

A pesquisa bibliográfica serviu como ponto de partida para a construção do referencial teórico da pesquisa sobre conceitos de acessibilidade e sobre segurança em situações de emergência que demandam o esvaziamento das edificações. Através dela, buscou-se compreender sobre comportamento humano em situações de risco, bem como as particularidades relacionadas a pessoas com mobilidade reduzida e a pessoas com deficiência visual, motora e auditiva.

Foram realizadas a leitura e a análise de artigos em periódicos e eventos, trabalhos de conclusão de curso, dissertações, normas e legislações vigentes, contemplando os principais pontos do estudo. Através da leitura de estudos acadêmicos, que realizaram visitas de campo/exploratórias, passeios acompanhados e aplicação de questionários/entrevistas, foram avaliadas as proposições pertinentes às normas estudadas.

No que se refere às normativas federais estudadas, além da NBR 9050:2015 referente a acessibilidade, seis normas relacionadas a prevenção e ao combate a incêndio foram preliminarmente levantadas: Saídas de emergência: NBR 9077:2001 (em revisão); Sinalização de Emergência: NBR 13434-1:2004 (em revisão); lluminação de emergência: NBR 10898:2013; Sistema de detecção e alarme de incêndio: NBR 17240:2010; Plano de emergência contra incêndio: NBR 15219:2005 (em revisão) e Brigada de incêndio: NBR 14276:2006 (em revisão). A partir destas seis normativas 
federais, foi realizada uma pesquisa sobre normativas estaduais em outras unidades da federação, a fim de estabelecer relações, observar padrões e elaborar proposições. Constatou-se que 15 estados possuem normativa específica sobre Saídas de emergência (56\% dos estados), 12 estados possuem normativa específica sobre Sinalização de emergência (44\%), 14 estados possuem normativa específica sobre lluminação de emergência (52\%), 12 estados possuem normativa específica sobre Sistema de detecção e alarme de incêndio (44\%), 9 estados possuem normativa específica sobre Plano de emergência contra incêndio (33\%) e 14 estados possuem normativa específica sobre Brigada de incêndio (52\%).

Optou-se pelo recorte para análise crítica e comparação das normas técnicas referentes às Saídas de emergência e à Brigada de incêndio, visto que ambas estão em processo de revisão em Santa Catarina e em nível federal. Além disso, há normativas estaduais em mais da metade dos estados.

Com base na metodologia utilizada por Pinto (2017), realizou-se uma busca por acessibilidade para pessoas com limitações físicas, auditivas e visuais nas normas que regem as instalações de combate a incêndio.

\section{ANÁLISE E INTERPRETAÇÃO DOS DADOS}

\section{NBR 9050:2015}

$\mathrm{Na}$ análise de referências relacionadas a emergências, incêndios, fugas, resgates e segurança, no texto da NBR 9050:2015, foi possível destacar quatro tópicos: Área de refúgio ou resgate, Rota de fuga, Sinalização e Alarmes.

No que diz respeito à Área de refúgio ou resgate, definida como área com acesso direto para uma saída, destinada a manter em segurança pessoas com deficiência ou com mobilidade reduzida, enquanto aguardam socorro em situação de sinistro, é possível dizer que,apesar da "Figura 64 - Área de resgate para pessoa com deficiência", o destaque está na "Figura 69 - Área reservada para cadeira de rodas em área de resgate - Exemplos". Na figura 69 
são representados quatro exemplos de área reservadas para cadeiras de rodas, sendo duas junto a escadas e duas junto a elevadores de emergência.

Sobre Rota de fuga, definida como trajeto contínuo, devidamente protegido, constituído por portas, corredores, antecâmaras, passagens externas, balcões, vestíbulos, escadas, rampas ou outros dispositivos de saída ou combinações destes, a ser percorrido pelo usuário, em caso de sinistro de qualquer ponto da edificação, até atingir uma área segura, destacou-se a frase "A rota acessível pode coincidir com a rota de fuga". A frase poderia ser "A rota de fuga coincide com uma das rotas acessíveis". Há um subtítulo específico para o tema, o "6.4 Rotas de fuga - Condições gerais", no qual está a figura 69 citada acima e no qual se vinculam as rotas de fuga ao atendimento ao disposto na ABNT NBR 9077 e outras regulamentações locais contra incêndio e pânico (Instruções Normativas do Corpo de Bombeiros Militar de Santa Catarina). Também se vinculam as portas de corredores, acessos, áreas de resgate, escadas de emergência e descargas integrantes de rotas de fuga acessíveis à obrigação de dotação de barras antipânico, conforme ABNT NBR 11785.

Na temática da Sinalização, há um subitem específico denominado 5.5 Sinalização de emergência, que apresenta orientações para sinalização de áreas de resgate e de espera para pessoas com deficiência, assim como sinalização de espaço para P.C.R. (pessoa em cadeira de rodas). $\mathrm{Na}$ classificação da sinalização de emergência é feita vinculação a NBR 13434 (todas as partes). Há referência para que em situações de incêndio, pânico e evacuação sejam observadas as normas estabelecidas pelo Corpo de Bombeiros. É orientada Sinalização Direcional na forma sonora, utilizando recursos de áudio para explanação de direcionamentos e segurança, como em alarmes e rotas de fuga. Considera rotas de fuga como elementos de sinalização essenciais. A "Tabela 1 - Aplicação e formas de informação e sinalização" indica sinalização permanente de emergência visual, tátil e sonora, assim como sinalização temporária de emergência visual e sonora. É indicada 
a Aplicação do Símbolo Internacional de Acesso (SIA) em áreas de assistência para resgate, áreas de refúgio e saídas de emergência. É orientada sinalização visual fotoluminescente ou retroiluminada, quando se tratar de Degraus de escadas de saídas de emergência e/ou rota de fuga.

No que tange aos Alarmes, há um subitem específico denominado 5.6 Alarmes, sendo indicada diferenciação de tom e frequência dos alarmes de emergência em relação ao alarme de incêndio.

Há menção para que os acessos sejam vinculados através de rota acessível à circulação principal e às circulações de emergência, que devem permanecer livres de quaisquer obstáculos de forma permanente.

A Instrução Técnica № 11/2004 - Saídas de Emergência (Corpo de Bombeiros) faz parte da Bibliografia citada na NBR 9050:2015.

\section{IN 009/DAT/CBMSC}

A IN 009/DAT/CBMSC tem como referência a NBR 9077:2001. Na NBR 9077:2001, a acessibilidade é vinculada ao ser referenciada a NBR 9050, no entanto, no restante do texto a normativa associa pessoa com deficiência a edificações classificadas como "serviços de saúde e institucionais" - grupo $\mathrm{H}$ $(\mathrm{H}-2$ - Locais onde pessoas requerem cuidados especiais por limitações físicas ou mentais) e a "Escolas para portadores de deficiências - Escolas para excepcionais, deficientes visuais e auditivos e outros" - grupo E6. A pesquisa de Silva et al. (2017) indica divergências nas indicações de parâmetro projetuais entre a NBR 9050 e a NBR9077, como também pode ser observado na presente pesquisa. Há referência a corrimãos intermediários, mas não a corrimão duplo. Indica que as rotas de saída destinadas ao uso de doentes e deficientes físicos, inclusive usuários de cadeiras de rodas, devem possuir rampas e elevadores de segurança ou outros dispositivos onde houver diferença de nível entre pavimentos, assim como pontua que para edificações do tipo $\mathrm{H}-1$ (hospitais veterinários), $\mathrm{H}-2$ e E-6, a comunicação entre as áreas de refúgio e/ou entre estas áreas e saídas deve ser em nível ou em rampas. $\mathrm{Na}$ 
Revista Científica do Corpo de Bombeiros Militar de Pernambuco

Artigo publicado no Vol.05 º12 - Edição de JAN a JUN 2019 - ISSN 2359-4829

Versão on-line disponível em: http://www.revistaflammae.com.

Tabela 5 - Dados para o dimensionamento das saídas, a ocupação E-6 tem a mesma capacidade de Unidades de passagem que as ocupações H-2 e H-3. Já na Tabela 6 - Distâncias máximas a serem percorridas, a ocupação E-6 não possui semelhança com nenhum outro tipo de ocupação. A NBR 9077 considera a instalação de alarmes, iluminação de emergência e sinalização adequada de todas as saídas de locais que são normatizados respectivamente pela NBR 17240, NBR 10898 e NBR 13434. Vale ressaltar que a NBR 9077 está em processo de revisão, sendo que a norma vigente data de 2001, portanto, possui um hiato em relação a duas revisões da NBR 9050 desde 2001.

No texto da IN 009/DAT/CBMSC proposto para a consulta pública (consulta pública 16/07/2018 a 16/10/2018), observou-se a inserção da questão da acessibilidade ao referenciar a NBR 9050 (norma Versão 28/03/2014 que está em vigor não faz esta referência) e inserir a Seção IV Área de resgate para pessoas portadoras de deficiência (Art. 62 e 63) no capítulo XI Escadas. Destacou-se ainda a representação da previsão de "área de resgate para pessoas portadoras de deficiência", com módulo de referência e símbolo internacional de acessibilidade para os casos de escada protegida (Art. 72 e 73 - Figuras 07 e 08), escada enclausurada (Art. 74 e 75 - Figura 09), escada à prova de fumaça (Art.76 e 77 - Figura 100), escada pressurizada (Art. 79 e 80 Figura 11), escada aberta externa (Art.84 - Figura 12) e elevador de emergência (Art. 90 e 91 - Figura 13). Considera a mobilidade associada a "ocupação hospitalar com internação ou com restrição de mobilidade", orientando para estes casos: Largura mínima das escadas de emergência, rampas, acessos (circulação ou corredor), descarga e passarela: 2,40m (Art. 15 III); Largura das portas que integram as rotas de saída: ter portas com largura livre que permita a passagem de macas e leitos sobre rodas (Art., $17 \mathrm{I}$ ); Corrimão intermediário: isento para facilitar o deslocamento de pessoas em macas. (Art. $39 \S 1^{\circ}$ ); Elevador de emergência: (Art. $90 \mathrm{VI}$ - Figura 13): cabine com comprimento interno mínimo de 2,20 m, a fim de permitir o transporte de 
maca; Tabelas: 05 - Tipo e quantidade de escadas de emergência; 06 Cálculo da lotação e capacidade de passagem das saídas de emergência; 07 Distâncias máximas a serem percorridas.

\section{IN 028/DAT/CBMSC}

A IN 028/DAT/CBMSC tem como referência a NBR 14276:2006, na qual não se observa menção à palavra acessibilidade. Além disso, observa-se que a palavra deficiente aparece apenas vinculada a classificação da ocupação "E-6 Escolas para portadores de deficiências - Escolas para excepcionais, deficientes visuais e auditivos e outros". Define pessoa com mobilidade reduzida e considera, no currículo mínimo do curso de formação de brigada de incêndio (anexo B.1), o objetivo da parte teórica como "Conhecer as técnicas de abordagem, cuidados e condução de acordo com o plano de emergência da planta".A tabela B.2 determina este mesmo conteúdo para os três níveis de treinamento. Referente à Composição da brigada de incêndio por pavimento ou compartimento (anexo A), para a ocupação E-6, determina toda a população fixa por pavimento ou compartimento, assim como nível intermediário de treinamento e de instalação (NBR14277 - Instalações e equipamentos para treinamento de combate a incêndio - Requisitos). Para a ocupação H2 determina toda a população fixa por pavimento ou compartimento, além de nível de treinamento e nível da instalação NBR 14277 básico para grau de risco baixo e médio, sendo indicado o nível intermediário para risco alto. Esta normativa está em processo de revisão.

No texto proposto para a consulta pública (versão proposta para consulta pública 27/07/2018 a 27/08/2018), observou-se a incorporação da questão da acessibilidade relacionada apenas à inserção do assunto "Cuidados com pessoas com mobilidade reduzida" no Currículo mínimo para a capacitação de brigadistas voluntários (Anexo C) e para a formação de brigadistas particulares e instrutores de brigadistas (Anexo C), observa-se que 
a mobilidade é associada à ocupação hospitalar com/sem internação ou com/sem restrição de mobilidade.

\section{CONCLUSÃO}

Em situações de emergência, torna-se necessário identificar as principais dificuldades no deslocamento de pessoas com deficiência,a fim de desenvolver estratégias para o deslocamento destas pessoas, visando sua proteção no local ou sua evacuação segura.

Considera-se que a acessibilidade é um tema transversal, que não demandaria normativa específica sobre o tema, mas é necessário que alguns pontos essenciais da NBR 9050:2015 se façam presentes nas normativas de segurança contra incêndio como forma de reiteração e para evitar conflitos entre diretrizes. No entanto, sabe-se que muitas vezes as normativas são revisadas em períodos distintos,o que torna mais difícil conciliar as atualizações. O mínimo a ser indicado é a referência ao número da NBR, o que, no caso das INS do CBMSC, não ocorre nas normas vigentes.

No estudo de caso realizado, optou-se por uma medida de proteção passiva (saídas de emergência) e por outra ativa (brigada de incêndio) e buscou-se a complementação, visto que os dois tipos de proteção são relevantes. Constatou-se que no caso da IN 009/DAT/CBMSC a acessibilidade se fez mais presente, no entanto, no caso da IN 028/DAT/CBMSC a questão apresentou menor avanço, pois aparenta ter se limitado a questão de deficiência/limitação físico-motora.

Ressalta-se que a pesquisa bibliográfica realizada indicou que a orientação espacial, como um dos componentes da acessibilidade espacial, está indissociável da comunicação, do uso e do deslocamento. Por isso, ao analisar as rotas de fugas é necessário realizar o cruzamento com as normativas relacionadas a sistemas de detecção e alarme (essenciais para percepção do risco, principalmente para pessoas com deficiência visual e 
Revista Científica do Corpo de Bombeiros Militar de Pernambuco

Artigo publicado no Vol.05 Nº12 - Edição de JAN a JUN 2019 - ISSN 2359-4829

Versão on-line disponível em: http://www.revistaflammae.com.

auditiva), assim como sistemas de iluminação, sinalização e plano de emergência.

Para além das normativas, as medidas de prevenção e combate serão cada vez mais eficientes e específicas para cada tipo de edificação, se forem incorporadas a rotina e a uma cultura de segurança, na qual o tema se faça presente e possa constantemente ser revisado.

\section{REFERÊNCIAS}

ASSOCIAÇÃO BRASILEIRA DE NORMAS TÉCNICAS (ABNT). NBR 9050: Acessibilidade a edificações, mobiliário, espaços e equipamentos urbanos. Rio de Janeiro: ABNT, 2015.

2011.

. NBR 9077. Saídas de emergência em edifícios. Rio de Janeiro: ABNT,

NBR 14276. Brigada de incêndio - Requisitos. Rio de Janeiro: ABNT, 2006.

BROMBILLA, Douglas de Castro. Evacuação Emergencial em Locais de Reunião de Público: Caso de Estádios de Futebol Brasileiros. Florianópolis, 2014. 235 p. Dissertação (Mestrado em Arquitetura e Urbanismo) - Programa de Pós-Graduação, Universidade Federal de Santa Catarina, 2014.

CORPO DE BOMBEIROS MILITAR DE SANTA CATARINA. Instrução Normativa IN 009/DAT/CBMSC: Sistema de saídas de emergência. Florianópolis: 2014a. Disponível em: https://dat.cbm.sc.gov.br/images/arquivo_pdf/IN/Em_vigor/IN_009_Saidas_de_ Emergncia_28mar2014.pdf. Acesso em 20 nov. 2018.

Instrução Normativa IN 028/DAT/CBMSC: Brigada de Incêndio. Florianópolis, 2014b. Disponível em https://dat.cbm.sc.gov.br/images/arquivo_pdf/IN/Em_vigor/IN_028_Brigada_de_ Incndio_28mar2014.pdf. Acesso em 20 nov. 2018.

DRURY, John; COCKING, Chris. The mass psychology of disasters and emergency evacuations: A research report and implications for practice. 2007. Tese (Doutorado) - Curso de N/s, Department Of Psychology, University Of Sussex, Brighton, 2007. Disponível em: $<$ https://www.researchgate.net/publication/253362722_The_Mass_Psychology_ 
Revista Científica do Corpo de Bombeiros Militar de Pernambuco

Artigo publicado no Vol.05 Nº12 - Edição de JAN a JUN 2019 - ISSN 2359-4829

Versão on-line disponível em: http://www.revistaflammae.com.

of_Disasters_and_Emergency_Evacuations_A_Research_Report_and_Implicat ions_for_Practice $>$. Acesso em: 10 mar. 2019.

DUARTE, Cristiane Rose de Siqueira; COHEN, R. Proposta de Metodologia de Avaliação da Acessibilidade aos Espaços de Ensino Fundamental. In: Anais NUTAU 2006: Demandas Sociais, Inovações Tecnológicas e a Cidade. São Paulo, USP: 2006.

FURUKAWA, Y. et al. Reproducibility of Group Evacuation Behaviour of the Elderly by Subjects Wearing Elderly Simulator. In: Asia - Oceania Symposium on Fire Science and Technology, $7^{\text {th }}$, Hong Kong. Anais ....Hong Kong, 2007. p. 1-14. Disponível em: <https://www.iafss.org/publications/aofst/7/116/view/aofst_7-116.pdf>. Acesso em: 10 mar. 2019.

GOUVEIA, Antônio; ETRUSCO, Paula. Tempo de escape em edificações: os desafios do modelamento de incêndio no Brasil. Revista Escola de Minas, Ouro Preto, v. 55, n. 4, p. 257-261, dez. 2002. Disponível em: <http://www.scielo.br/pdf/rem/v55n4/v55n4a05.pdf>. Acesso em: 10 mar. 2019.

HAMILTON, B Ooz Allen et al. (Orgs.). Routes to Effective Evacuation Planning Primer Series: Evacuating Populations with Special Needs. Washington: U. S. Department Of Transportation, 2009. Disponível em: <https://ops.fhwa.dot.gov/publications/fhwahop09022/fhwahop09022.pdf>. Acesso em: 10 mar. 2019.

KINATEDER, Max $T$ et al. Risk perception in fire evacuation behavior revisited: definitions, related concepts, and empirical evidence. Fire Science Reviews, [s.I.], v. 4, n. 1, p.1-26, 8 jan. 2015. Springer Science + Business Media. Disponível em: $<\mathrm{https}$ ://firesciencereviews.springeropen.com/articles/10.1186/s40038-0140005-Z>. Acesso em: 10 mar. 2019.

LIMA, Maria Luiza Tremel de Faria. Esvaziamento emergencial de locais ocupados por pessoas com mobilidade reduzida: estudo aplicado a edificações hospitalares. Florianópolis, 2017. Dissertação (Mestrado em Arquitetura e Urbanismo) - Programa de Pós-Graduação, Universidade Federal de Santa Catarina, 2017.

NATIONAL FIRE PROTECTION ASSOCIATION. Emergency Evacuation Planning Guide for People with Disabilities. NFPA. EUA, 2016. Disponível em: $\quad<$ https://www.nfpa.org/-/media/Files/Public-Education/Bytopic/Disabilities/EvacuationGuidePDF.ashx?la=en>. Acesso em: 20 nov. 2018. 
NEVES, S.; LEÇA COELHO, A.; RODRIGUES, J. P. Evacuação em caso de incêndio de pessoas com limitações. Proteger, Lisboa [APSEI] $=2008$ - , 1647-1288, № 10 (2011), p. 32-38.

PINTO, Maria do Socorro Lopes. Acessibilidade em instalações de combate a incêndio. 2017. Artigo científico (Graduação) - Universidade Federal do Rio Grande do Norte, Centro de Tecnologia, Departamento de Engenharia Civil, Natal, 2017.

PROULX, Guylène. Evacuation Planning for Occupants with Disability.
Ottawa, 2002. <http://www.mingerfoundation.org/downloads/general/proulx\%20disability\%20pl anning.pdf>. Acesso em: 10 mar. 2019.

REIS, Maria do Rosário Frazão. Estudo da evacuação em caso de incêndio de edifícios que recebem público: o caso do shopping center Fórum Coimbra. Coimbra, 2014. Dissertação (Mestre em Segurança ao Incêndio Urbano) - Departamento de Engenharia Civil, FCTUC, 2014.

SAMOSHIN, D.; ISTRATOV, R. The Characteristics of Blind and Visually Impaired People Evacuation in Case of Fire. Fire Safety Science, v. 11, p. 1160-1169, 2014.2 Disponível em: <http://iafss.org/publications/fss/11/1160/view/fss_11-1160.pdf>. Acesso em: 10 mar. 2019.

SILVA, E. C. M.; PINTO, E. M.; HOLANDA, M. C.Conflitos entre as normas brasileiras de acessibilidade e saídas de emergência. In: Congresso IberoLatino Americano sobre Segurança Contra Incêndio, 4, 2017, Recife. Anais....v. 4.Olinda: Livro Rápido, 2017. p. 455-463.

TSUCHIYA, S.; HASEMI, Y.; FURUKAWA, Y. Evacuation Characteristics Of Group With Wheelchair Users. In:Asia - Oceania Symposium on Fire Science and Technology, $7^{\text {th }}$, Hong Kong. Anais .... Hong Kong, 2007. p. 1-12. Disponível em: <https://www.iafss.org/publications/aofst/7/117/view/aofst_7117.pdf >. Acesso em: 10 mar. 2019.

VALENTIM, M. V.; ONO, R. Qualidade do projeto de saídas de emergência em edificações para pessoas com deficiência. In: Encontro Nacional de Tecnologia do Ambiente Construído, XV,2014, Maceió. Anais.... Maceió, 2014. p. 1943$1952 . \quad$ Disponível em: <http://www.infohab.org.br/entac2014/artigos/paper_204.pdf>. Acesso em 20 nov. 2018. 